\title{
Optimizing Planting Density and Impact of Panicle Types on Grain Yield and Microclimatic Response Index of Hybrid Rice (Oryza sativa L.)
}

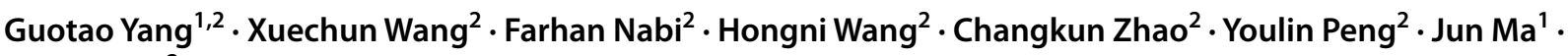 \\ Yungao $\mathrm{Hu}^{2}$
}

Received: 21 February 2021 / Accepted: 13 July 2021 / Published online: 24 July 2021

(c) The Author(s) 2021

\begin{abstract}
The architecture of rice plant represents important and complex agronomic traits, such as panicles morphology, which directly influence the microclimate of rice population and consequently grain yield. To enhance yield, modification of plant architecture to create new hybrid cultivars is considered a sustainable approach. The current study includes an investigation of yield and microclimate response index under low to high plant density of two indica hybrid rice R498 (curved panicles) and R499 (erect panicles), from 2017 to 2018. The split-plot design included planting densities of $11.9-36.2 \mathrm{plant} / \mathrm{m}^{2}$. The results showed that compared with R498, R499 produced a higher grain yield of 8.02-8.83 t/ha at a higher planting density of 26.5-36.2 plant $/ \mathrm{m}^{2}$. The response index of light intensity and relative humidity to the planting density of R499 was higher than that of R498 at the lower position of the rice population. However, the response index of temperature to the planting density of R499 was higher at the upper position (0.2-1.4\%) than at the lower position. Compared with R498, R499 at a high planting density developed lower relative humidity (78-88\%) and higher light intensity (9900-15,916 lx) at the lower position of the rice population. Our finding suggests that erect panicles are highly related to grain yield microclimatic contributors under a highly dense rice population, such as light intensity utilization, humidity, and temperature. The application of erect panicle rice type provides a potential strategy for yield improvement by increasing microclimatic conditions in rice.
\end{abstract}

Keywords Environmental condition $\cdot$ Ear of rice $\cdot$ Canopy $\cdot$ Ecological niches $\cdot$ Climatic factors

\section{Introduction}

Rice (Oryza sativa L.) is one of the essential cereal crops, supplying more than $21 \%$ of the nutritional needs of the world population. It is a staple food in Asia, accounting for approximately $47.8 \%$ in productivity and $38.5 \%$ in planting areas of total cereal crops worldwide (Chen et al., 2019).

Guotao Yang and Farhan Nabi contributed equally to this work and should be considered co-first authors

Jun Ma

majunp2002@163.com

Yungao $\mathrm{Hu}$

344704158@qq.com

1 Sichuan Agricultural University, Chengdu 611130, Sichuan, China

2 College of Life Science and Engineering, Southwest University of Science and Technology, Mianyang 621010, Sichuan, China
Increasing planting area or improving grain yield per unit area was the general method to produce more food to ensure global food security. However, according to d'Amour et al. (2017)'s urban expansion will result in a $1.8-2.4 \%$ loss of global croplands by 2030 , and approximately $80 \%$ of global cropland loss will take place in Asia and Africa due to climate change and worldwide urbanization. Shi et al. (2016) reported that the widespread urban expansion in China has consumed $33,080 \mathrm{~km}^{2}$ of agricultural land during 2000-2013. Therefore, increasing the yield per unit area has become a heated debate on rice research.

Like different irrigation methods, fertilizer and planting density also had a significant impact on the microclimate of rice population which ultimately impact the panicle number per unit area, spikelet number per panicle, percentage of filled grains, and 1000-grain weight of rice, which at last determine the yield of rice per unit area. Conventional nitrogen and phosphorous fertilizer relieved the nutrition stress on the rice yield, which helped rice to build a better microclimate in rice population and helped the farmer to produce 
more grain yield in rice fields during the last 20 years worldwide (Yang et al., 2018). Besides water and fertilizer, planting density also had a great impact on the rice population in the field. Previous studies proved that dense planting has been recommended as a promising practice for achieving greater grain yield, and it is recommended as a practice for achieving greater grain yield with fewer resource inputs for rice (Huang et al., 2018), wheat (Triticum aestivum L.) (Li et al., 2016), canola (Brassica napus L.) (L. Wang et al. 2015), and maize (Zea mays L.) (Shi et al., 2016).

More attention has been paid globally to regulating suitable and competitive relationships among plants to increase grain yield by modifying planting density (D. Wang et al., 2014). The previous studies focused on the relationship between dense planting and yield, most studies concluded that dense planting resulted in low yield as compared to sparse planting (Huang et al., 2009; Nakano et al., 2012). Similar results were found by Clerget et al. (2016) and Huang et al. (2018), in which they found an increase of density from 15 to $40 \mathrm{plant} / \mathrm{m}^{2}$ resulted in low rice grain yield. However, previous studies have also found that increasing planting density can reduce weight per panicle and the total number of grains (Hayashi et al., 2006; Nakano et al., 2012). Lu et al. (2020) believe that planting density only has a significant impact on effective panicle number, seed setting rate, and grain number per panicle.

From full heading to maturity, the canopy of the rice population is always occupied by panicles. With an increase in the panicle bending angle and planting density, the panicle shading area and canopy enclosure result in reduced light transmittance that leads to low light energy utilization efficiency, which is not favorable for the heading and mature stage of rice (Yang et al., 2018). Besides planting density, the bending angle of the panicle is another key factor that affects the shading of the panicle on the canopy of the rice population. Compared with a curved panicle, an erect panicle provides more free space for the canopy and lets more light reach the lower part of the rice population. Chen et al. (2014) proposed that designing crop canopies to make the maximum use of solar radiation and periods with favorable temperatures is critical to improving yield with less input, which could be achieved by bringing erect panicle rice types into practice. At present, japonica rice, which has an erect or semi-erect panicle, is broadly being planted in Northeast China (Liang et al., 2017; Zhao et al., 2016). Generally, the erect panicles found in the japonica rice types, and the curved panicle are reported in the indica rice types. However, with the development of crossbreeding technology, some new erect panicle rice has been reported in the indica rice. In this study, one erect panicle indica hybrid rice $\mathrm{R} 499$ produced in a previous study from indica hybrid rice R498 (Yang et al., 2018) was assessed for yield and microclimatic response under low to high planting density.
This erect panicle indica rice has a different canopy structure from the curved panicle rice; reasonably using this in different ways can help farmers to build a better and healthier population to produce more food in a unit area.

This paper aims to understand the differences between erect panicles and curved panicles rice types in the microclimate response of rice population to planting density by investigating the temperature, relative humidity, and light for various parts of the rice population under different planting densities. Moreover, it also seeks to provide some suggestions for farmers on how to produce a higher grain yield of rice by controlling the planting density of erect panicle indica rice.

\section{Material and Methods}

\section{Study Area}

Mianyang $\left(104.73^{\circ} \mathrm{E}, 31.47^{\circ} \mathrm{N}\right)$, located at the middle and upper reaches of the Fujiang River (Wang et al., 2020), has a typical subtropical monsoon climate, with an average annual temperature of $14.7-17.3{ }^{\circ} \mathrm{C}$ and average annual precipitation of 826-1417 mm. Its soil is typical clay-loam soil, with a bulk density of $1.29 \mathrm{~g} / \mathrm{cm}^{3}$ and organic matter content of $28.6 \mathrm{~g} / \mathrm{kg}$; its total nitrogen content is $1.68 \mathrm{~g} / \mathrm{kg}$, the total phosphorus is $0.37 \mathrm{~g} / \mathrm{kg}$, and the total potassium is $1.86 \mathrm{~g} /$ $\mathrm{kg}$, in 0-50 cm soil.

\section{Experimental Design}

The experiment was carried out in the agricultural experimental field of SWUST University at Mianyang from 2017 to 2018. R499 and R498 were selected as the typical erect panicle rice and the typical curved panicle rice for this experiment. From R498 (Shuhui498), we previously produced its mutated type R499 by the EMS mutagenesis technique (Yang et al., 2018). The rice types R498 and R499 are similar in other morphological traits except for their panicle types, which are different. R499 and R498 were sowed in early April and transplanted into the field in the middle of May. To avoid the impacts of seedling quality on rice growth, only strong and healthy seedlings which had 3 tillers (at least) with similar quality were selected to be transplanted into field plots.

The five treatments including plant space $(\mathrm{m})$ designated as D0 $(0.40 \mathrm{~m} \times 0.21 \mathrm{~m})$, D1 $(0.38 \mathrm{~m} \times 0.20 \mathrm{~m})$, D2 $(0.33 \mathrm{~m} \times 0.17 \mathrm{~m}), \mathrm{D} 3(0.27 \mathrm{~m} \times 0.14 \mathrm{~m}), \mathrm{D} 4$ $(0.23 \mathrm{~m} \times 0.12 \mathrm{~m})$, with $11.9,13.2,18,26.5$ and 36.3 planting density (plant $/ \mathrm{m}^{2}$ ) were proposed for R499 and R498 in this study, respectively (Yang et al., 2018).

The experiment was established as a split-plot design with rice variety as the main factor and planting density as 
the split-plot factor. All the experiments were established in 3 replicates with 30 plots, the size of each plot was $5 \mathrm{~m} \times 6.5 \mathrm{~m}$. Nitrogen (N), Phosphorous (P), and Potassium (K) applied for each plot were the same with $150 \mathrm{~kg} / \mathrm{ha} \mathrm{N}, 38.7 \mathrm{~kg} / \mathrm{ha} \mathrm{P}$, and $99.6 \mathrm{~kg} / \mathrm{ha} \mathrm{K}$, respectively. Nitrogen fertilizer (urea) was applied as base fertilizer, tiller fertilizer, and panicle fertilizer in the ratio of 5:3:2; potassium fertilizer (potassium chloride) was applied as base fertilizer and panicle fertilizer in the ratio of 1:1; phosphorus fertilizer (calcium superphosphate) was applied as base fertilizer along with soil tillage before transplanting rice. Water was irrigated with shallow water at the tilling stage, booting stage, and full-filling stage (1:1:1); there was no irrigation for other growth periods of rice growth.

\section{Sampling and Measurement}

\section{Light Intensity, Temperature, and Humidity}

Temperature, relative humidity, and light intensity were measured at the full heading and maturity stage in 2017 and 2018 by sensors and rapid equipment. The sensors were located at the upper and lower position in the canopy, which was defined as $4 / 5$ and $1 / 5$ of the total canopy height, respectively. The temperature and humidity of the canopy were measured by Pt 1000 sensor, while light intensity was measured by TASI-8720 LUX Luminance digital light intensity meter.

\section{Yield and Yield Components Measurement}

After rice maturation, 20 plants (repeated three times) were randomly sampled and air-dried from each treatment for yield determination. The average number of panicles was counted; panicles of 5 rice plants were collected, air-dried, and used to determine the effective panicle, grain weight per panicle, grain number per panicle, seed setting rate, 1000-grain weight, and other yield components.

$80 \%$ of rice heading in plots was considered as the full heading stage, and $90 \%$ of rice maturity was considered as the maturity stage. Grain yield and yield components including spikelet fertility were determined at harvest.

\section{Data Processing and Analysis}

The response of temperature, humidity, and light intensity in rice population toward planting densities was calculated from Eqs. 1, 2, and 3, respectively.

$$
R T \varepsilon_{n}=\frac{T \varepsilon_{n}-T \varepsilon_{n-1}}{T \varepsilon_{n-1}} n \geq 1, \varepsilon=\text { UandL }
$$

$R H \varepsilon_{n}=\frac{H \varepsilon_{n}-H \varepsilon_{n-1}}{H \varepsilon_{n-1}} n \geq 1, \varepsilon=\operatorname{Uand} L$

$R L \varepsilon_{n}=\frac{L \varepsilon_{n}-L \varepsilon_{n-1}}{L \varepsilon_{n-1}} n \geq 1, \varepsilon=$ Uand $L$

RT $\varepsilon_{n}$, Relative response index of temperature. RH $\varepsilon_{n}$, Relative response index of humidity. RL $\varepsilon_{n}$, Relative response index of light intensity. where $\varepsilon$ denotes the position of sensors, $\mathrm{U}$ the upper position, and $\mathrm{L}$ the lower position in the rice population.

$\mathrm{T} \varepsilon_{\mathrm{n}-1}, \mathrm{H} \varepsilon_{\mathrm{n}-1}$, and $\mathrm{L} \varepsilon_{\mathrm{n}-1}$ denote the temperature, humidity, and light intensity of rice population at a planting density of $\mathrm{D}_{\mathrm{n}-1} ; \mathrm{n}=0$ means a planting density of $11.9 \mathrm{plant} /$ $\mathrm{m}^{2}$; and $\mathrm{n}=1,2,3$ and 4 means a planting density of 13.2, 18.0, 26.5 and $36.2 \mathrm{plant} / \mathrm{m}^{2}$. Mean values of each microclimate in 2017 and 2018 were used to analyze the impact of plant density and panicle types on microclimate in the rice population.

For statistical analysis, and graphical representation Excel 2016 and ANOVA were performed to evaluate the difference between plant density treatments and panicle types.

\section{Results}

\section{The Influence of Planting Density on Yield and Yield Components}

R499 produced a higher grain yield than R498 at a higher planting density from 26.5 to $36.2 \mathrm{plant} / \mathrm{m}^{2}$, either in 2017 or in 2018 (Table 1). However, the lowest grain yield was recorded in low planting density for both rice cultivars. R498 favored D2 density for high grain yield (7.95-8.09 t/ ha) and effective panicles $\left(108.7-130.4 \times 10^{6} \mathrm{P} / \mathrm{ha}\right)$, while $\mathrm{R} 499$ had the highest grain yield of $8.42-8.83$ t/ha at D3 density (Fig. 1). The statistical analysis for yield components showed planting density had no significant effect on seed setting rate, and 1000-grain weight, except for, weight per panicle (6.02-9.72 g) and grain number per panicle (190-297), which decreased with an increase in density in both years for both cultivars. The results of seed setting rate and 1000grain weight in 2018 were higher than that in 2017, which is affected by the climate difference between the two years.

\section{The Influence of Different Planting Densities on the Light Intensity of Rice Population}

The polynomial regression analysis order 2 of light intensity at the upper position of the rice population decreased with the increase of planting density during the full heading or maturity stage (Fig. 2a, c). When the planting density 
Table 1 Effects of planting density on yield components and yield

\begin{tabular}{|c|c|c|c|c|c|c|c|c|}
\hline Year & Rice variety & Treatments & Yield (t/ha) & $\begin{array}{l}\mathrm{EFP}\left(\times 10^{6}\right. \\
\text { panicles/ha) }\end{array}$ & WPP (g) & GNP & SSR (\%) & TGW (g) \\
\hline \multirow[t]{10}{*}{2017} & \multirow[t]{5}{*}{ R498 } & D0 & $6.55 \mathrm{c}$ & $84.2 \mathrm{~d}$ & $9.72 \mathrm{a}$ & $297 \mathrm{a}$ & $86 \mathrm{a}$ & $33.0 \mathrm{a}$ \\
\hline & & D1 & $6.68 \mathrm{c}$ & $99.8 \mathrm{c}$ & $8.42 \mathrm{~b}$ & $286 \mathrm{~b}$ & $87 \mathrm{a}$ & $33.1 \mathrm{a}$ \\
\hline & & D2 & $8.09 \mathrm{a}$ & $108.7 \mathrm{a}$ & $8.45 \mathrm{~b}$ & $282 \mathrm{bc}$ & $87 \mathrm{a}$ & $32.8 \mathrm{a}$ \\
\hline & & D3 & $7.49 \mathrm{~b}$ & $105.8 \mathrm{ab}$ & $8.43 \mathrm{~b}$ & $279 \mathrm{c}$ & $86 \mathrm{a}$ & $32.9 \mathrm{a}$ \\
\hline & & D4 & $7.15 \mathrm{~b}$ & $104.7 \mathrm{~b}$ & $8.02 \mathrm{~b}$ & $256 \mathrm{~d}$ & $87 \mathrm{a}$ & $32.9 \mathrm{a}$ \\
\hline & \multirow[t]{5}{*}{ R499 } & D0 & $6.12 \mathrm{~d}$ & $84.6 \mathrm{~d}$ & $8.21 \mathrm{a}$ & $261 \mathrm{a}$ & $91 \mathrm{a}$ & $33.0 \mathrm{a}$ \\
\hline & & D1 & $6.59 \mathrm{c}$ & $89.1 \mathrm{c}$ & $7.32 \mathrm{~b}$ & $228 \mathrm{~b}$ & $90 \mathrm{a}$ & $32.9 \mathrm{a}$ \\
\hline & & D2 & $7.59 \mathrm{~b}$ & $96.8 \mathrm{~b}$ & $7.55 \mathrm{~b}$ & $223 b$ & $90 \mathrm{a}$ & $32.9 \mathrm{a}$ \\
\hline & & D3 & $8.42 \mathrm{a}$ & $112.0 \mathrm{a}$ & $7.28 \mathrm{~b}$ & $195 \mathrm{c}$ & $91 \mathrm{a}$ & $32.8 \mathrm{a}$ \\
\hline & & D4 & $8.02 \mathrm{~b}$ & $109.0 \mathrm{a}$ & $7.13 \mathrm{~b}$ & $190 \mathrm{c}$ & $90 \mathrm{a}$ & $32.8 \mathrm{a}$ \\
\hline \multirow[t]{10}{*}{2018} & \multirow[t]{5}{*}{ R498 } & D0 & $5.73 \mathrm{~d}$ & $105.8 \mathrm{c}$ & $7.21 \mathrm{a}$ & $254 \mathrm{a}$ & $88 \mathrm{a}$ & $34.0 \mathrm{a}$ \\
\hline & & D1 & $6.27 \mathrm{c}$ & $121.2 \mathrm{~b}$ & $6.42 \mathrm{ab}$ & $251 \mathrm{a}$ & $87 \mathrm{a}$ & $34.0 \mathrm{a}$ \\
\hline & & D2 & $7.95 \mathrm{a}$ & $130.4 \mathrm{a}$ & $6.72 \mathrm{a}$ & $228 \mathrm{~b}$ & $87 \mathrm{a}$ & $34.1 \mathrm{a}$ \\
\hline & & D3 & $7.52 \mathrm{~b}$ & $119.0 \mathrm{~b}$ & $6.33 \mathrm{ab}$ & $224 \mathrm{~b}$ & $87 \mathrm{a}$ & $34.1 \mathrm{a}$ \\
\hline & & D4 & $7.45 \mathrm{~b}$ & $113.1 \mathrm{c}$ & $6.11 \mathrm{~b}$ & $201 \mathrm{c}$ & $88 \mathrm{a}$ & $34.0 \mathrm{a}$ \\
\hline & \multirow[t]{5}{*}{ R499 } & D0 & $5.68 \mathrm{~d}$ & $105.8 \mathrm{c}$ & $7.15 \mathrm{a}$ & $219 \mathrm{a}$ & $91 \mathrm{a}$ & $34.0 \mathrm{a}$ \\
\hline & & D1 & $6.07 \mathrm{c}$ & $106.9 \mathrm{c}$ & $6.82 \mathrm{ab}$ & $208 \mathrm{a}$ & $90 \mathrm{a}$ & $34.0 \mathrm{a}$ \\
\hline & & D2 & $7.67 \mathrm{~b}$ & $115.3 \mathrm{~b}$ & $6.31 \mathrm{bc}$ & $193 \mathrm{~b}$ & $90 \mathrm{a}$ & $34.1 \mathrm{a}$ \\
\hline & & D3 & $8.83 \mathrm{a}$ & $130.4 \mathrm{a}$ & $6.02 \mathrm{c}$ & $194 \mathrm{~b}$ & $91 \mathrm{a}$ & $33.9 \mathrm{a}$ \\
\hline & & D4 & $8.56 \mathrm{a}$ & $129.1 \mathrm{a}$ & $6.46 \mathrm{bc}$ & $190 \mathrm{~b}$ & $91 \mathrm{a}$ & $34.0 \mathrm{a}$ \\
\hline
\end{tabular}

Yield and yield components of R499 curved and R498 erect panicle rice in the year of 2017 and 2018. Different plant space $(\mathrm{m})$ and abbreviation showed as a DO $11.9\left(\mathrm{plant} / \mathrm{m}^{2}\right), D 113.2\left(\mathrm{plant} / \mathrm{m}^{2}\right), D 218(\mathrm{plant} /$ $\mathrm{m}^{2}$ ), D3 26.5 (plant $\left./ \mathrm{m}^{2}\right), D 436.2\left(\mathrm{plant} / \mathrm{m}^{2}\right), E F P$ effective panicle, WPP grain weight per panicle, GNP grain number per plant, SSR seed setting rate, $T G W 100$-grain weight. Values within a column followed by different letters were different at $\mathrm{p}<0.05$
Fig. 1 The difference between R498 curved and R499 erect panicle rice showed the plant architecture (a) and panicles shape (b)
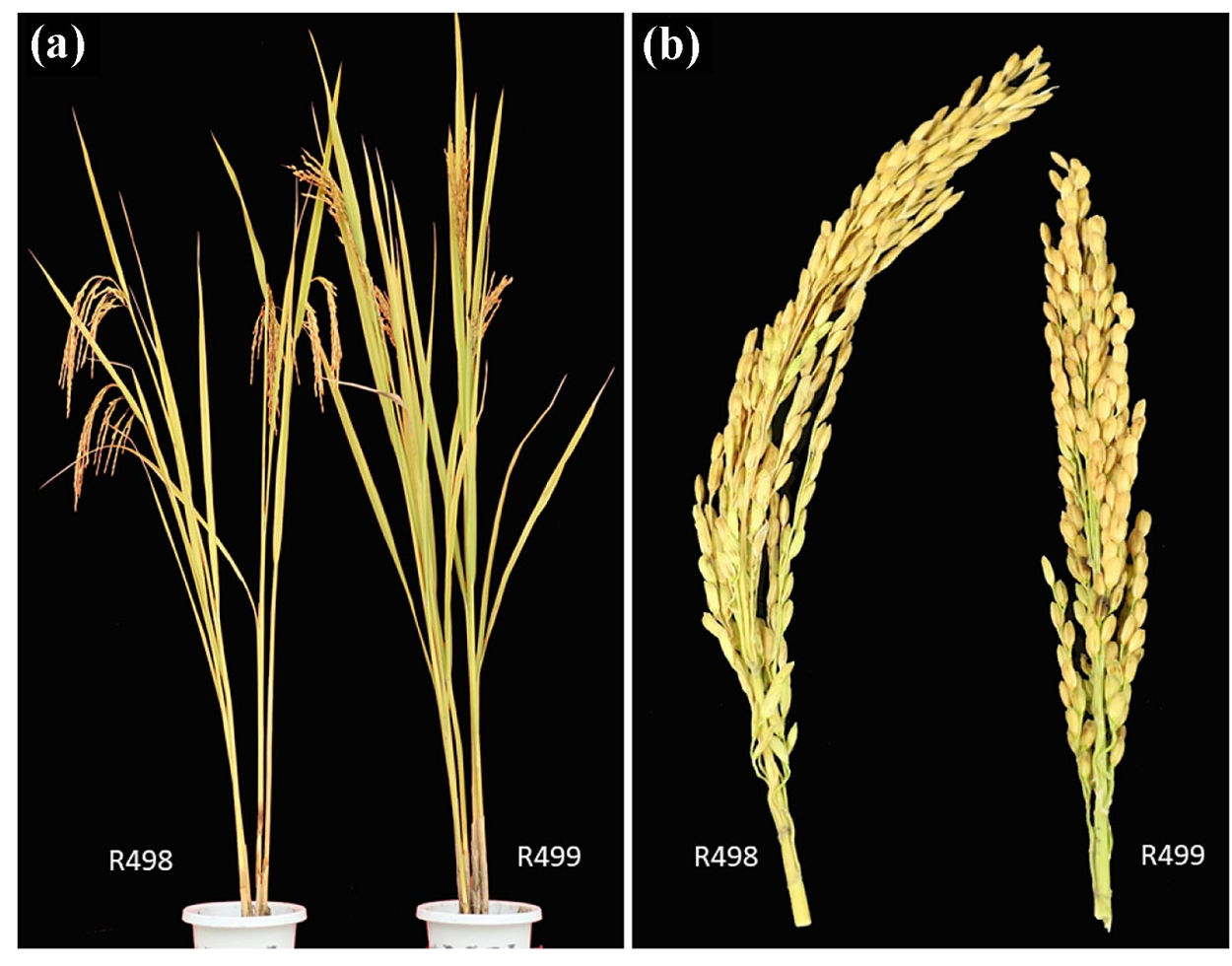

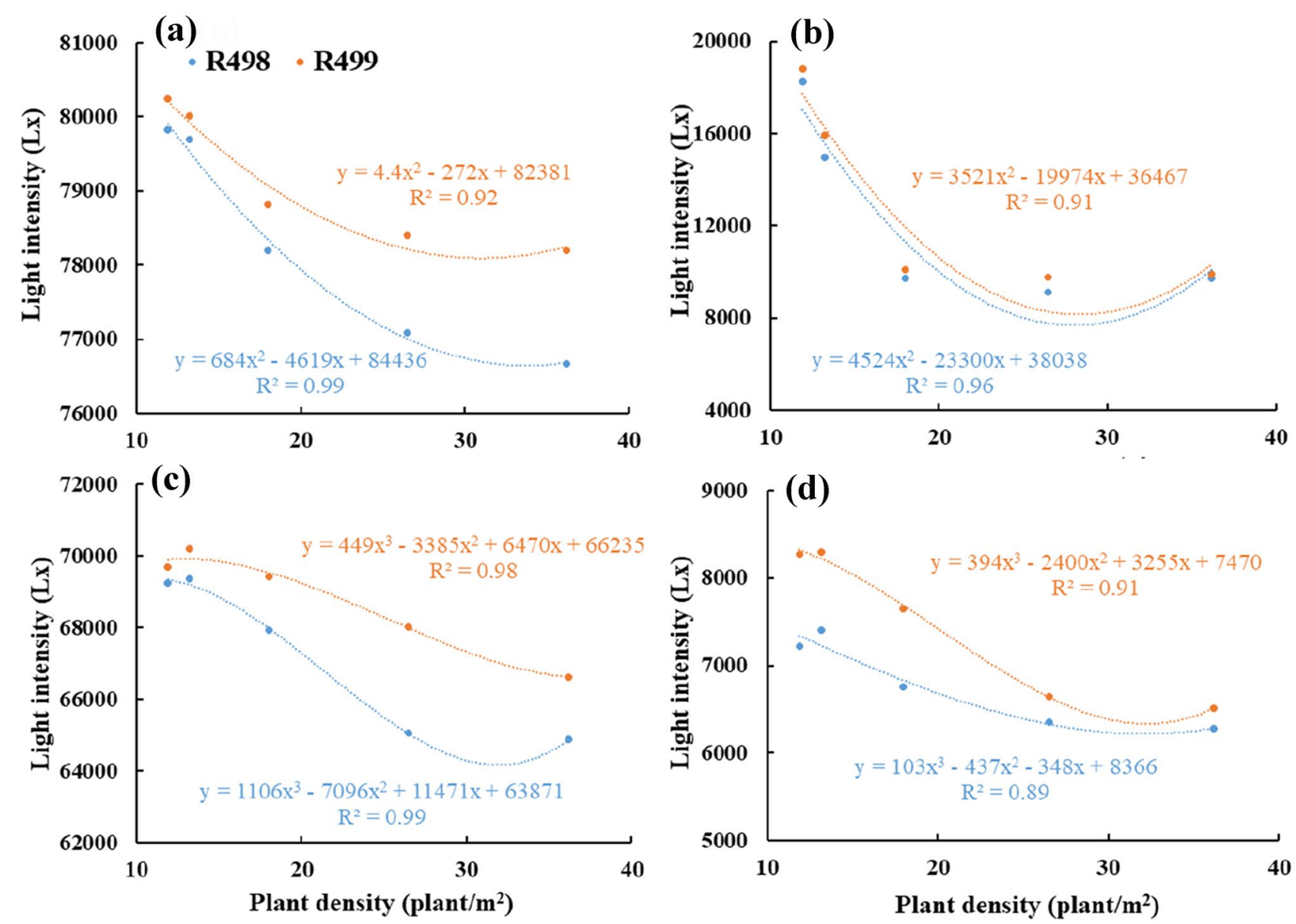

Fig. 2 The effect of planting density on the average light intensity at the upper (a and $\mathbf{c}$ ) and lower (b and d) position of rice population during full heading (a and b) and maturity (c and d) stage

increased from 11.9 to $36.2 \mathrm{plant} / \mathrm{m}^{2}$, the light intensity at the upper position of the R499 population decreased from 80,250 to $78,200 \mathrm{~lx}\left(R^{2}=0.92\right)$; this decreasing rate was significantly lower than that of R498 from 79,833 to $76,657 \mathrm{~lx}\left(\mathrm{R}^{2}=0.99\right)$. During the full heading stage, the dynamic change of light intensity at the lower position of R499 was similar to that of R498; both followed a downward trend from 11.9 to $36.2 \mathrm{plant} / \mathrm{m}^{2}$ (Fig. 2b); however, during the maturity stage, the dynamic of light intensity at the lower position of $R 499\left(R^{2}=0.91\right)$ was different from $R 498$ $\left(\mathrm{R}^{2}=0.89\right)$ (Fig. 2d).

During the full heading as well as maturity stage, compared with R498, R499 always showed a higher light intensity from lower to higher planting density at both the lower and upper positions of the rice population. The response index of light intensity to the planting density was higher at the lower position of rice population (Fig. 3b, d) as compared to the upper position of rice population (Fig. 3a, c). During the full heading or maturity stage, when the plant density increased from 13.2 to $36.2 \mathrm{plant} / \mathrm{m}^{2}$, R498 showed a higher response index of light intensity to the planting density at the upper position than R499 (Fig. 3a, c). While during the maturity stage, when the planting density increased from 13.2 to $36.2 \mathrm{plant} / \mathrm{m}^{2}$, R499 showed a higher response index of light intensity to the planting density than R498 at the lower position (Fig. 3d). These outcomes mean that the light intensity at the lower position of R499 was more sensitive to the planting density than R498 at the higher planting density (13.2-36.2 plant $\left./ \mathrm{m}^{2}\right)$.

\section{The Effect of Different Planting Densities on the Temperature of Rice Population}

The polynomial regression showed with the increase of planting density, R499 and R498 showed similar dynamic changes $\left(R^{2}=0.93,0.92\right)$ of temperature to the planting density at the lower position of the rice population (Fig. 4b, $\mathrm{d})$, while this was different at the upper position of the rice population $\left(\mathrm{R}^{2}=0.79,0.83\right)$ (Fig. $\left.4 \mathrm{a}, \mathrm{c}\right)$. Compared with R498, R499 always showed a higher temperature at the 


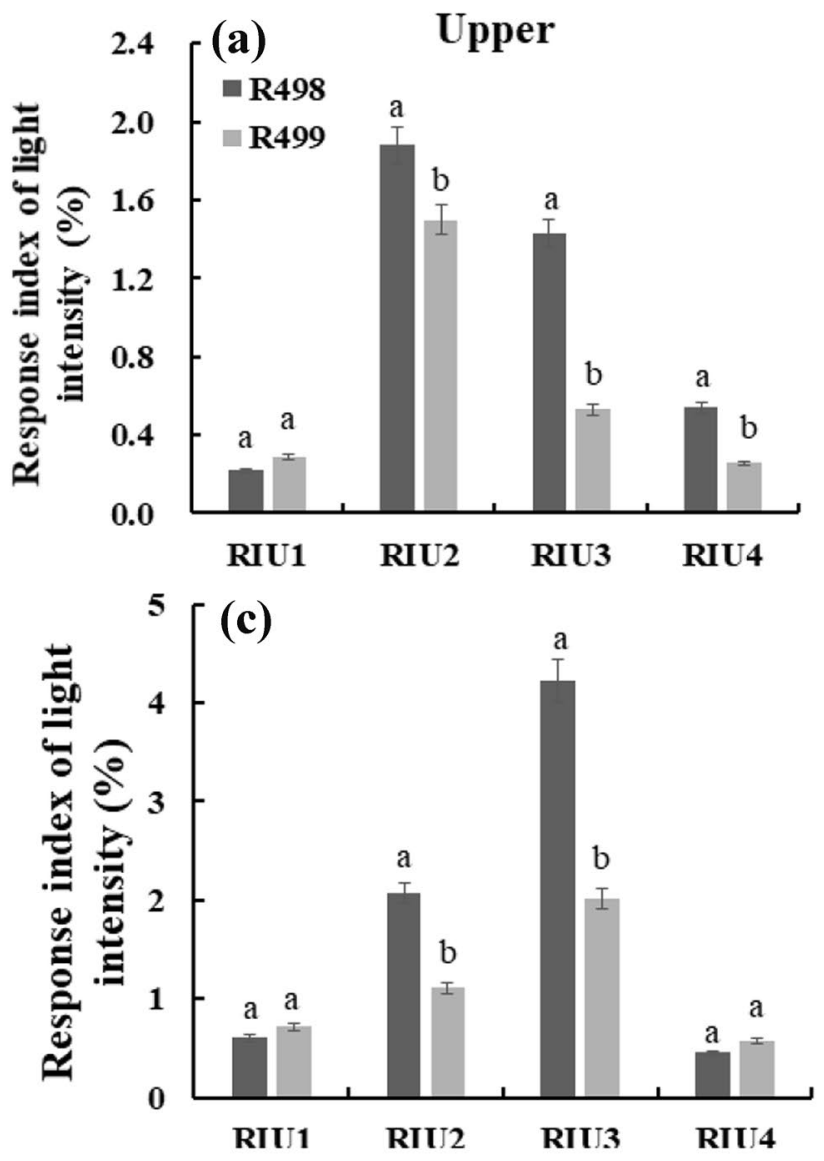

Fig. 3 RIU = Response index of light intensity at upper position; $\mathrm{RIL}=$ Response index of light intensity at lower position. Mean response index of light intensity to plant density at upper (a and $\mathbf{c}$ )

lower position of the rice population $\left(\mathrm{R}^{2}=0.98\right)(\mathrm{Fig} .4 \mathrm{~b}, \mathrm{~d})$; however, it showed a decrease in temperature at the upper position of the rice population specifically during the maturity stage (Fig. 4c).

During the maturity stage, with the increase of the planting density, the temperature at the upper position of the R498 population decreased from 25.2 to $24.7{ }^{\circ} \mathrm{C}$, while it decreased from 24.7 to $24.6{ }^{\circ} \mathrm{C}$ in the population of $\mathrm{R} 499$ $\left(\mathrm{R}^{2}=0.93\right)$. The temperature at the lower position of the $\mathrm{R} 498\left(\mathrm{R}^{2}=0.85\right)$ population increased from 23.7 to $23.8^{\circ} \mathrm{C}$; similarly, it increased from 23.8 to $24.7^{\circ} \mathrm{C}$ in the population of $\mathrm{R} 499\left(\mathrm{R}^{2}=0.98\right)$.

The response index of temperature to the planting density was higher at the upper position (Fig. 5a, c) than that at the lower position of the rice population (Fig. 5b, d). This indicates that the temperature at the upper position of the rice population was more susceptible to plant density than the lower position of the rice population. When planting density increased from 18.0 to 36.2 plant $/ \mathrm{m}^{2}$, R498 always showed a higher response index of temperature to the planting density than R499 in the upper position of rice population, in

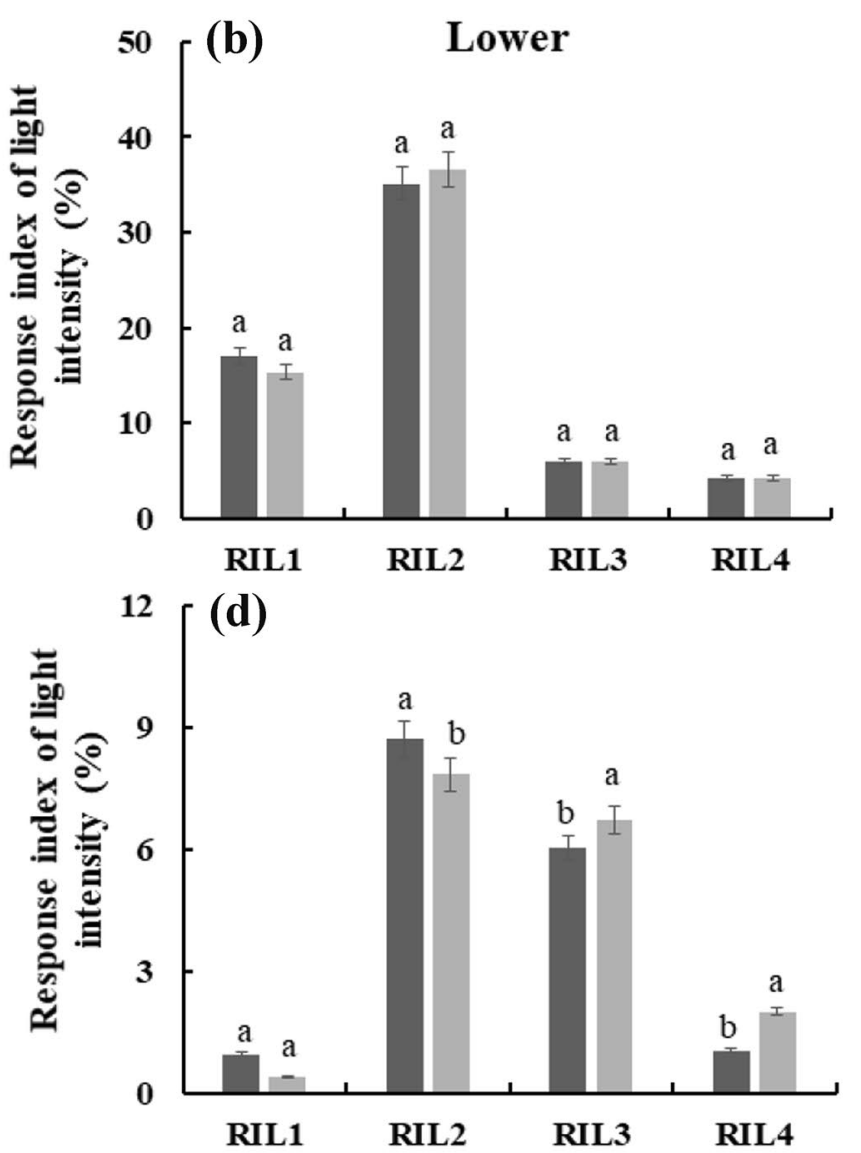

and lower (b and $\mathbf{d}$ ) position of rice population during full heading (a and b) and maturity (c and d) stage. The S.E. was calculated across two years. Different letters indicate significant differences at $p<0.05$

both the full heading and maturity stage (Fig. 5a, c). When the planting density increased from 13.2 to $26.5 \mathrm{plant} / \mathrm{m}^{2}$, R498 showed a higher response index of temperature to the planting density than R499 in the lower position of the rice group, in both the full heading and maturity stage (Fig. 5b, d); however, there was no significant difference when the planting density increased from 26.5 to 36.2 plant $/ \mathrm{m}^{2}$.

\section{The Influence of Planting Density on the Relative Humidity of Rice Population}

In the case of humidity, the polynomial regression analysis showed as the planting density increased, a similar increasing trend was found in the relative humidity of R498 and R499 at the upper position of rice population, in both the full heading stage $\left(\mathrm{R}^{2}=0.82, \mathrm{R}^{2}=0.85\right)$ and maturity stage $(\mathrm{R} 2=0.99)($ Fig. $6 \mathrm{a}, \mathrm{c})$. However, it was different at the lower position, especially during the heading stage (Fig. 6d). During the heading stage, the relative humidity of $\mathrm{R} 499\left(\mathrm{R}^{2}=0.81\right)$ was lower than that of $\mathrm{R} 498$ $\left(\mathrm{R}^{2}=0.95\right)$ at the lower position of the rice population 

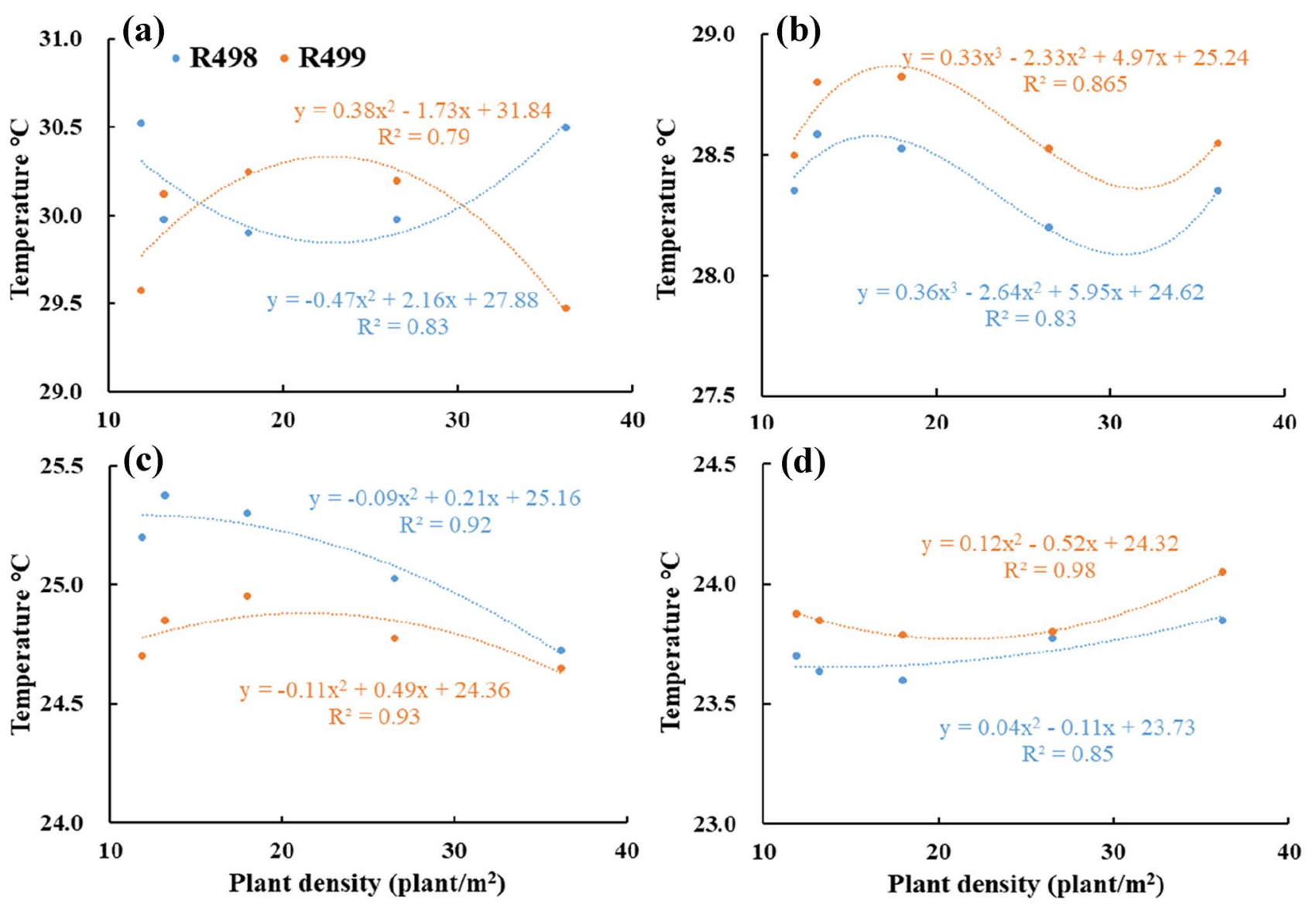

Fig. 4 The effect of planting density on the average temperature at upper (a and $\mathbf{c}$ ) and lower (b and $\mathbf{d})$ position of rice population during full heading ( $\mathbf{a}$ and $\mathbf{b}$ ) and maturity (c and $\mathbf{d}$ ) stage

(Fig. 6b, d); these outcomes indicate that R499 was better to build a lower relative humidity environment at the lower position of rice population.

During the maturity stage, with the increase of planting density, the relative humidity of R499 and R498 both showed an increasing trend at either the upper or lower position of the rice population (Fig. 6a, b). Similar results were found at the upper position of the rice population during the maturity stage, while it showed a different trend at the lower position.

The response index of relative humidity to planting density at the full heading stage, either the upper position or the lower position, appeared as a downtrend in both populations of R498 and R499 (Fig. 7a and b). When planting density increased from 11.9 to $36.2 \mathrm{plant} / \mathrm{m}^{2}$, the response index of relative humidity to plant density decreased from 76.6 to $81.8 \%$ at the upper position; this changing distance was significantly higher than that at the lower position (from $85.2 \%$ to $87.9 \%$ ). This indicates that the planting density produced more impacts to the relative humidity at the upper position than that at the lower position during the full heading stage.
The response index of relative humidity to the planting density showed a similar changing trend from lower to higher planting density during the maturity stage; both appeared as a downtrend after an increasing trend (Fig. 7c and d). However, the response index of relative humidity to the planting density of R499 was lower than that of R498 at the upper position of the rice population (Fig. 7c) and was higher than that of R498 at the lower position of the rice population (Fig. 7d).

\section{Discussion}

Rice grain yield per unit area is the most important indicator for evaluating the effects of different rice planting measures. Rice institutes in China had a focus on regulating the suitable and competitive relationships among plants to increase grain yield by modifying planting density for decades (Wang et al., 2014). Previous studies reported that increasing plant density promotes plant biomass (Weiner, 2004). Dense planting and sparse planting are the main variables between panicle number per unit area and grain number per panicle. 


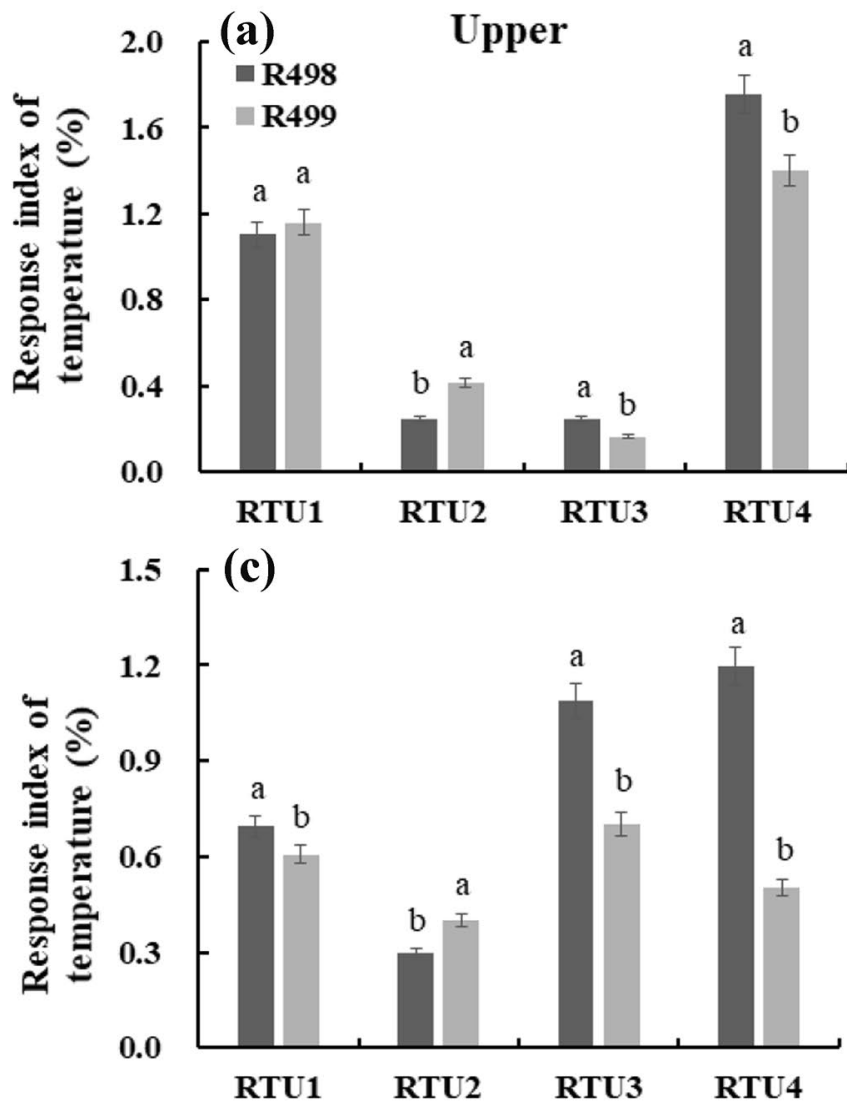

Fig. $5 \mathrm{RTU}=$ Response index of temperature at upper position; $\mathrm{RTL}=$ Response index of temperature at lower position. Mean response index of temperature to plant density at upper (a and c) and

Clerget et al. (2016) found that an appropriate increase in planting density resulted in higher rice yield and an effective number of panicles per unit area. However, some studies have found that increasing planting density can reduce weight per panicle and the total number of grains, meanwhile, there is no significant difference in seed setting rate under different density treatments found (Hayashi et al., 2006; Nakano et al., 2012; San-Oh et al., 2008).

Data from the current study showed compared with R498, $\mathrm{R} 499$ produced more grain yield at a higher planting density of $26.5-36.2 \mathrm{plant} / \mathrm{m}^{2}$, with a yield of $8.02-8.83 \mathrm{t} / \mathrm{ha}$. Similarly, effective panicle results were consistent with yield, while other yield component traits showed, no significant effect on weight per panicle, seed setting rate percentage, and thousand-grain weight, with exception of grain number per panicle, which decreased with increase in density in both years for both cultivars. The highly dense planting resulted in an inverse relationship between yield components and planting density. A similar negative relationship was also found in previous studies (Huang et al., 2009; Nakano et al., 2012). In this study, different planting densities and panicle types have extremely significant effects on rice yield. An appropriate
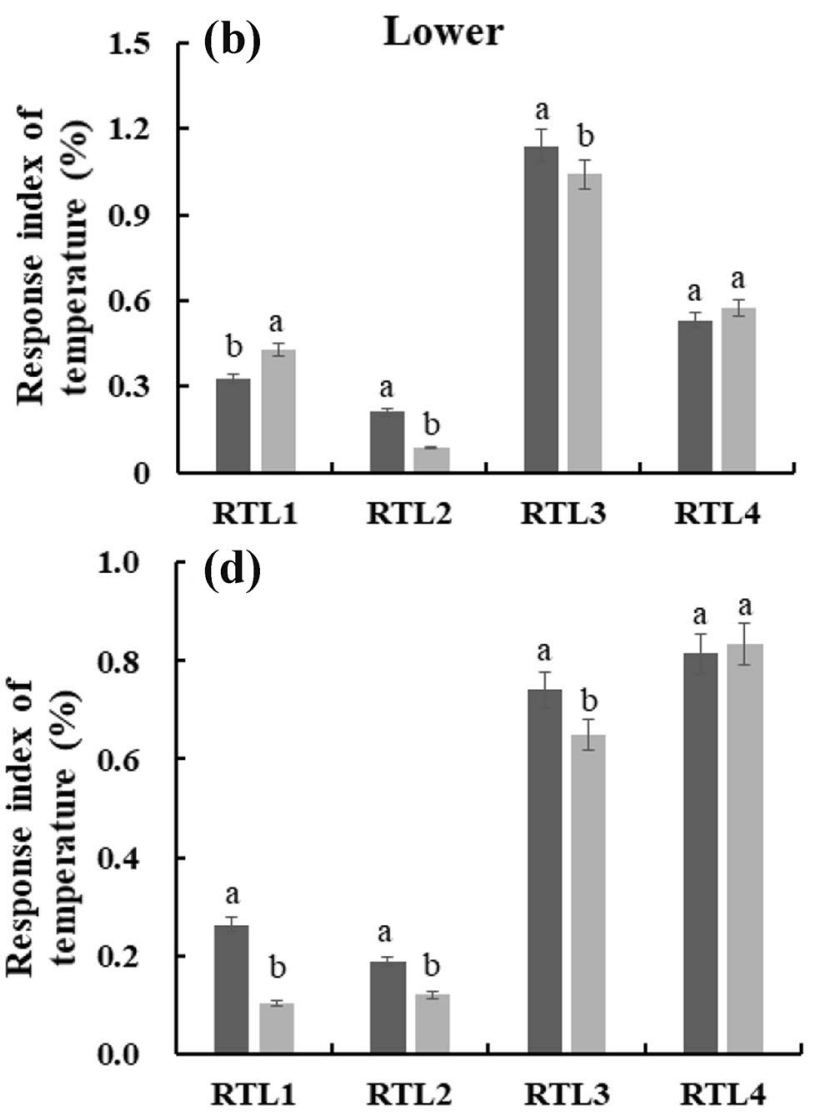

lower (b and $\mathbf{d}$ ) position of rice population during full heading (a and b) and maturity (c and d) stage. The S.E. was calculated across two years. Different letters indicate significant differences at $p<0.05$

increase in planting density can increase rice yield. This is consistent with the results of Zheng et al (2020) and Ao et al (2019), while erect panicle (R499), proved to be better for highly dense planting practices.

Improving the morphological characteristics of rice is one of the key factors in increasing its grain yield (Wang et al., 2009); therefore, the study of microclimatic conditions responsible for such contributors is essential. Previous reports have revealed that increasing rice population planting density often reduces the transfer of light from the canopy to the lower part of the rice population, and as the rice plant grows, the canopy of the rice population tends to be compact. As the light could not find proper space to enter, the rate of light intensity at the lower part decreases significantly, which affected the light utilization of the rice population in the current study. Compared with R498, there was more light transfer from the upper to the lower position in the rice population of R499; the response index of light intensity to the planting density of R499 was higher in the higher planting density. These results indicated that R499 provides more sufficient light intensity for the lower position of the rice population, which 

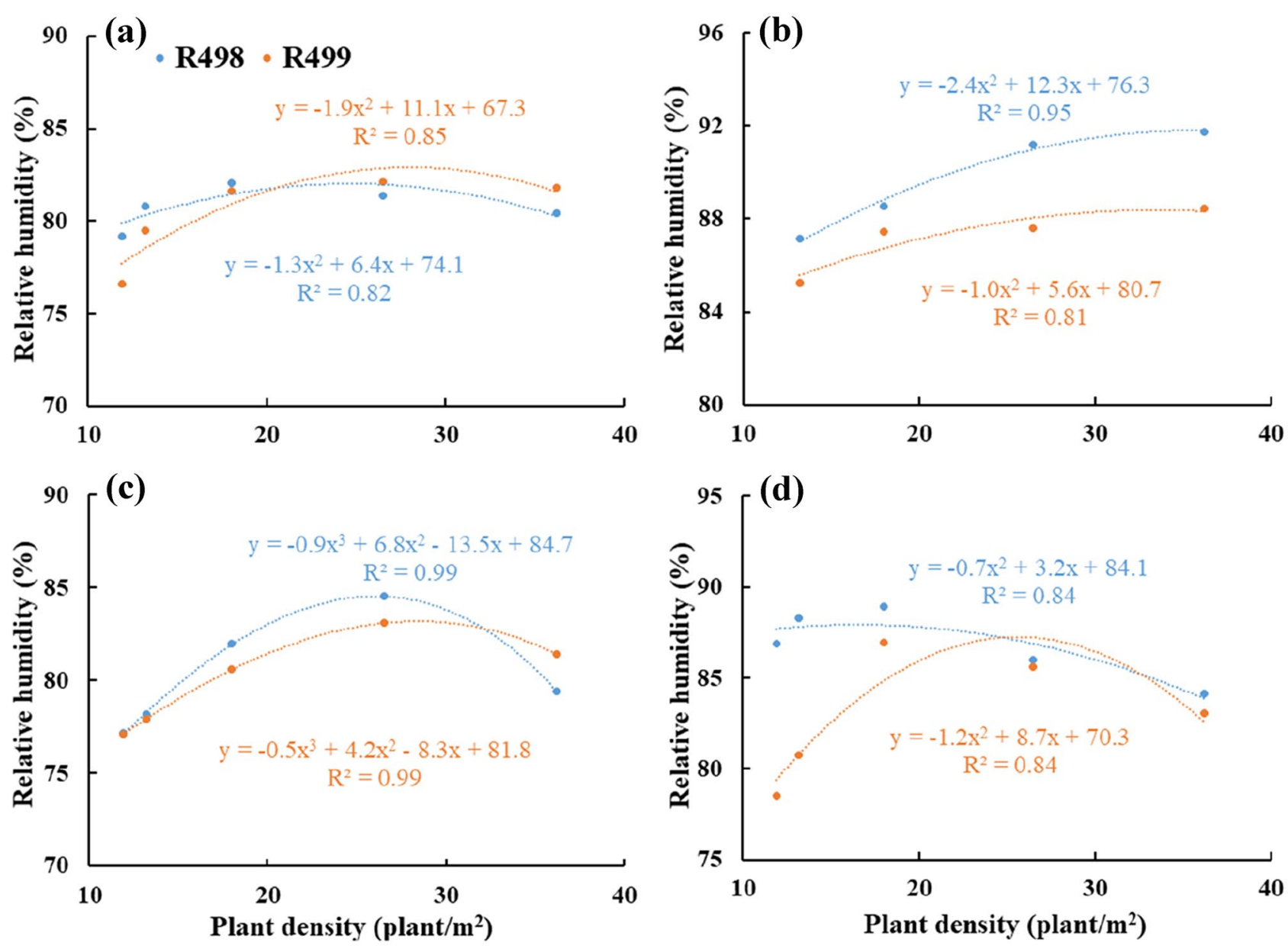

Fig. 6 The effect of planting density on the relative humidity at the upper (a and $\mathbf{c}$ ) and lower (b and d) position of rice population during full heading ( $\mathbf{a}$ and $\mathbf{b}$ ) and maturity (c and $\mathbf{d}$ ) stage

was better for the transportation of photosynthetic product from leaves and stem to the grain of rice; which ultimately improved the yield of rice (Chen et al., 2014).

The grain filling stage is one of the key stages during full heading. Chen et al (2019) found that during full heading lower canopy temperature highly favored chlorophyll content by the formation and transportation process of photosynthetic products, which ultimately increased rice yield.

The canopy temperature of R499 was lower than R498 during the maturity stage, and its temperature response index was lower than R498 in all densities (Fig. 4b and d). Garrity and O'Toole (1995) and Chauhan et al. (1999) have reported a negative correlation between yield and canopy temperature during the grain filling stage. The erect panicles population received higher light radiation than the curved panicles; the temperature at the lower position of R499 was higher than R498. The lower temperature at the canopy and higher temperature at the lower part of the rice population were better for the yield production of R499 at a higher planting density.
Increasing the planting density weakened the exchange rate of air and water from rice to the outside environment, which increased the relative humidity within the rice population. The higher humidity not only affects the vitality of the pollen and prevents the anther from rapture (Weerakoon et al., 2008) but also promotes the occurrence of microbial diseases such as sheath blight (Molla et al., 2020). During the maturity stage, the relative humidity of R499 was lower than R498 at the lower position of the rice population (Fig. 6b, d); these outcomes indicate that R499 was better to build a lower relative humidity environment at a lower position than $\mathrm{R} 498$.

\section{Conclusion}

Our study has demonstrated that erect panicles were highly favorable to grain yield and microclimatic contributors. More specifically, low temperature at the upper position, high temperature, and light intensity at the lower position 

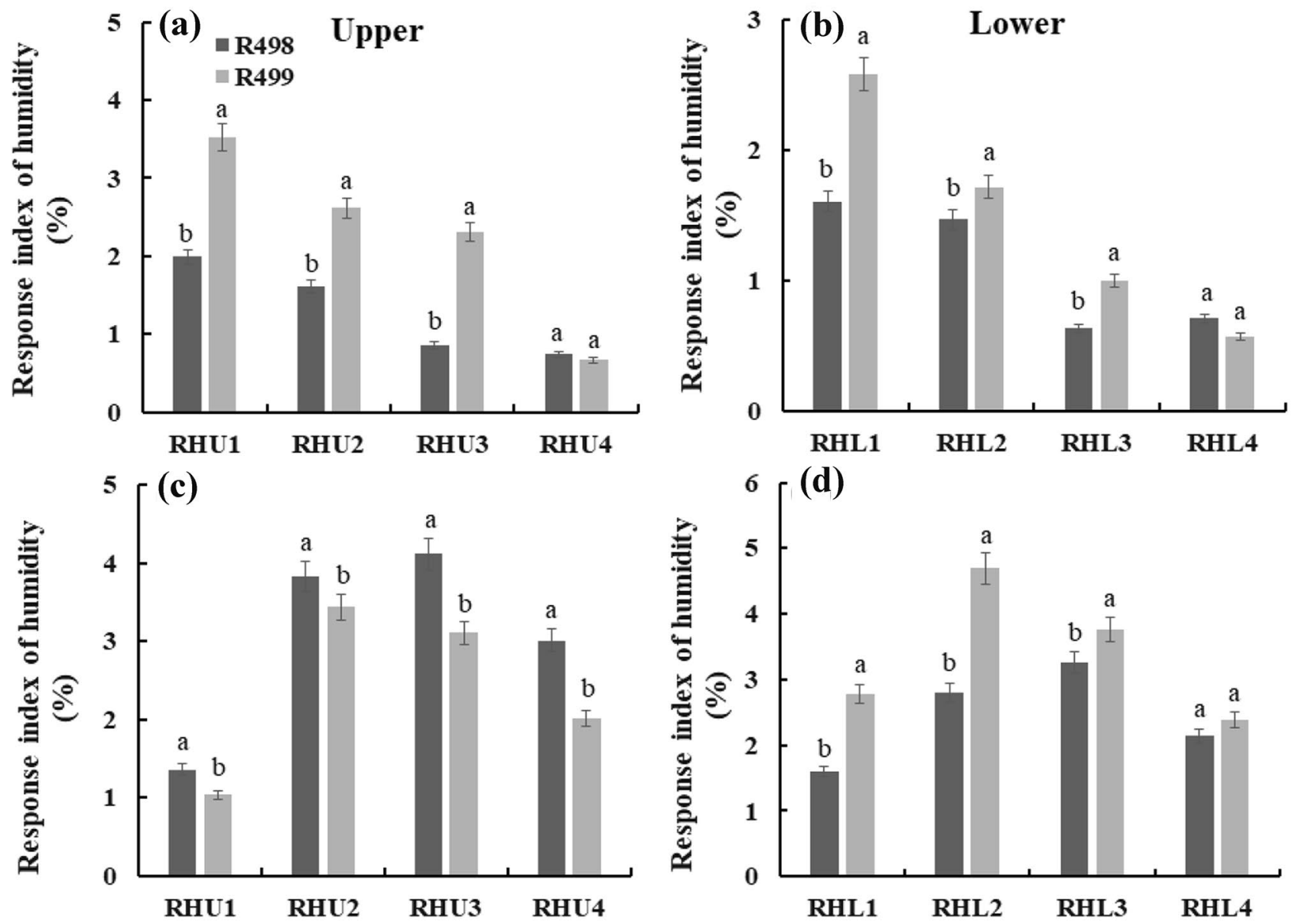

Fig. 7 RHU = Response index of humidity at upper position; $\mathrm{RHL}=$ Response index of humidity at lower position. Mean response index of relative humidity to plant density at upper (a and c) and

lower (b and d) position of rice population during full heading (a and b) and maturity (c and d) stage. The S.E. was calculated across two years. Different letters indicate significant differences at $p<0.05$

of R499 (erect panicles) provided better microclimate conditions in the population and produced higher grain yield than R498 (curved panicles) at a high planting density.

Also, we found, light intensity and relative humidity at the lower position of the rice group were more sensitive to the planting density than that at the upper position. However, surprisingly the temperature at the upper position was more sensitive to the high planting density than that at the lower position. These results specified that plant architecture is highly responsible for microclimatic contributors. Thus, accounting for these important factors we concluded that, erect panicles R499 were more suitable for higher planting density than curved panicles R498 in the humid and hot region of Sichuan Basin area.

Acknowledgements Special thanks are extended to the staff of the agricultural station of SWUST for their irreplaceable work to manage the experiment field and to collect the samples. We would also like to thank the reviewers and editor who provided valuable suggestions to improve this paper.
Funding The National Key Research and Development Program of China (2017YFD0301706; 2017YFD0301701; 2018YFD0301202) supported this work. The National Natural Science Foundation of China (31401347), and Sichuan Science and Technology Program (2021YFN0049; 2021NZZJ0024; 2021YFN0053).

\section{Declarations}

Conflict of Interest The authors declare there are no conflicts of interest.

Open Access This article is licensed under a Creative Commons Attribution 4.0 International License, which permits use, sharing, adaptation, distribution and reproduction in any medium or format, as long as you give appropriate credit to the original author(s) and the source, provide a link to the Creative Commons licence, and indicate if changes were made. The images or other third party material in this article are included in the article's Creative Commons licence, unless indicated otherwise in a credit line to the material. If material is not included in the article's Creative Commons licence and your intended use is not permitted by statutory regulation or exceeds the permitted use, you will 
need to obtain permission directly from the copyright holder. To view a copy of this licence, visit http://creativecommons.org/licenses/by/4.0/.

\section{References}

Ao, H., Xie, X., Huang, M., \& Zou, Y. (2019). Decreasing hill density combined with increasing nitrogen rate led to yield decline in hybrid rice under low-light conditions. Scientific Reports, 9(1), 1-5. https://doi.org/10.1038/s41598-019-52376-2

Chauhan, J., Moya, T., Singh, R., \& Singh, C. (1999). Influence of soil moisture stress during reproductive stage on physiological parameters and grain yield in upland rice. Oryza, 36(2), 130-135.

Chen, H., Li, Q. P., Zeng, Y. L., Deng, F., \& Ren, W. J. (2019). Effect of different shading materials on grain yield and quality of rice. Scientific Reports, 9(1), 1-9. https://doi.org/10.1038/ s41598-019-46437-9

Chen, X., Cui, Z., Fan, M., Vitousek, P., Zhao, M., Ma, W., et al. (2014). Producing more grain with lower environmental costs. Nature, 514(7523), 486-489. https://doi.org/10.1038/nature13609

Clerget, B., Bueno, C., Domingo, A. J., Layaoen, H. L., \& Vial, L. (2016). Leaf emergence, tillering, plant growth, and yield in response to plant density in a high-yielding aerobic rice crop. Field Crops Research, 199, 52-64. https://doi.org/10.1016/j.fcr. 2016.09.018

Garrity, D. P., \& O'Toole, J. C. (1995). Selection for reproductive stage drought avoidance in rice, using infrared thermometry. Agronomy Journal, 87(4), 773-779. https://doi.org/10.2134/agronj1995. $00021962008700040027 x$

Hayashi, S., Kamoshita, A., \& Yamagishi, J. (2006). Effect of planting density on grain yield and water productivity of rice (Oryza sativa L.) grown in flooded and non-flooded fields in Japan. Plant Production Science, 9(3), 298-311. https://doi.org/10.1626/pps.9.298

Huang, M., Chen, J., Cao, F., \& Zou, Y. (2018). Increased hill density can compensate for yield loss from reduced nitrogen input in machine-transplanted double-cropped rice. Field Crops Research, 221, 333-338. https://doi.org/10.1016/j.fcr.2017.06.028

Huang, X., Qian, Q., Liu, Z., Sun, H., He, S., Luo, D., et al. (2009). Natural variation at the DEP1 locus enhances grain yield in rice. Nature Genetics, 41(4), 494-497. https://doi.org/10.1038/ng.352

Li, Y., Shao, X., Guan, W., Ren, L., Liu, J., Wang, J., et al. (2016). Nitrogen-Decreasing and Yield-Increasing Effects of Combined Applications of Organic and Inorganic Fertilizers under Controlled Irrigation in a Paddy Field. Polish Journal of Environmental Studies, 25(2), 673-680. https://doi.org/10.15244/pjoes/61530

Liang, T., Xu, Z.j., \& Chen, W.f. (2017). Advances and prospects of super rice breeding in China. Journal of Integrative Agriculture, 16(5), 984-991. https://doi.org/10.1016/S2095-3119(16)61604-0

Lu, J., Wang, D., Liu, K., Chu, G., Huang, L., Tian, X., et al. (2020). inbred varieties outperformed hybrid rice varieties under dense planting with reducing nitrogen. Scientific Reports, 10(1), 1-13. https://doi.org/10.1038/s41598-020-65574-0
Molla, K. A., Karmakar, S., Molla, J., Bajaj, P., Varshney, R. K., Datta, S. K., et al. (2020). Understanding sheath blight resistance in rice: The road behind and the road ahead. Plant Biotechnology Journal, 18(4), 895-915. https://doi.org/10.1111/pbi.13312

Nakano, H., Morita, S., Kitagawa, H., Wada, H., \& Takahashi, M. (2012). Grain yield response to planting density in forage rice with a large number of spikelets. Crop Science, 52(1), 345-350. https://doi.org/10.2135/cropsci2011.02.0071

San-Oh, Y., Kondo, M., Ookawa, T., \& Hirasawa, T. (2008). Ecophysiological analysis on effect of planting pattern on biomass production and grain yield in rice. Japan Agricultural Research Quarterly: JARQ, 42(2), 79-89. https://doi.org/10.6090/jarq.42.79

Shi, K., Chen, Y., Yu, B., Xu, T., Li, L., Huang, C., et al. (2016). Urban expansion and agricultural land loss in China: a multiscale perspective. Sustainability, 8(8), 790. https://doi.org/10.3390/su808 0790

Wang, J., Nakazaki, T., Chen, S., Chen, W., Saito, H., Tsukiyama, T., et al. (2009). Identification and characterization of the erect-pose panicle gene EP conferring high grain yield in rice (Oryza sativa L.). Theoretical and Applied Genetics, 119(1), 85-91. https://doi. org/10.1007/s00122-009-1019-0

Wang, D., Chen, S., Wang, Z., Ji, C., Xu, C., Zhang, X., et al. (2014). Optimizing hill seeding density for high-yielding hybrid rice in a single rice cropping system in South China. PLOS ONE, 9(10), e109417. https://doi.org/10.1371/journal.pone.0109417

Wang, H., Yang, G., Wang, X., Zhao, C., Muhammad, N., Chen, Y., et al. (2020). Oilseed rape straw returning changes soil reducibility and affects the root and yield of rice in the rape-rice rotation field at Sichuan Basin area of China. Agronomy Journal, 112(6), 4681-4692. https://doi.org/10.1002/agj2.20408

Weerakoon, W., Maruyama, A., \& Ohba, K. (2008). Impact of humidity on temperature-induced grain sterility in rice (Oryza sativa L.). Journal of Agronomy and Crop Science, 194(2), 135-140. https:// doi.org/10.1111/j.1439-037X.2008.00293.x

Weiner, J. (2004). Allocation, plasticity and allometry in plants. Perspectives in Plant Ecology, Evolution and Systematics, 6(4), 207-215. https://doi.org/10.1078/1433-8319-00083

Yang, G., Wang, X., Peng, Y., Rasul, F., Hu, Y., \& Zou, T. (2018). Different micro-climate response of indica rice population to nitrogen fertilizer. Plant, Soil and Environment, 64(9), 407-412. https:// doi.org/10.17221/422/2018-PSE

Zhao, M., Sun, J., Xiao, Z., Cheng, F., Xu, H., Tang, L., et al. (2016). Variations in DENSE AND ERECT PANICLE 1 (DEP1) contribute to the diversity of the panicle trait in high-yielding japonica rice varieties in northern China. Breeding Science, 16058. https:// doi.org/10.1270/jsbbs. 16058

Zheng, H., Chen, Y., Chen, Q., Li, B., Zhang, Y., Jia, W., et al. (2020). High-density planting with lower nitrogen application increased early rice production in a double-season rice system. Agronomy Journal, 112(1), 205-214. https://doi.org/10.1002/agj2.20033 